\title{
Adhesive Resistance to Peeling Force of PTFE/PDMS Laminated Sheet Assisted by Homogeneous Low Voltage Electron Beam Irradiation at $77 \mathrm{~K}$
}

\author{
Chisato Kubo ${ }^{1, *}$, Takumi Okada ${ }^{1, *}$, Masato Uyama ${ }^{1, *}$, Masae Kanda $^{2}$ and Yoshitake Nishi ${ }^{1,2}$ \\ ${ }^{1}$ Graduate School of Engineering, Tokai University, Hiratsuka 259-1292, Japan \\ ${ }^{2}$ School of Engineering, Tokai University, Hiratsuka 259-1292, Japan
}

\begin{abstract}
The effects of homogeneous low voltage electron beam irradiation (HLEBI) under liquid nitrogen on the adhesive force of peeling $\left({ }^{\circ} F_{\mathrm{p}}\right)$ at accumulative probability of peeling $\left(P_{\mathrm{p}}\right)$ of laminated PTFE/PDMS sheets of polytetrafluoroethylene (PTFE) and polydimethylsiloxane (PDMS) at $77 \mathrm{~K}$ were investigated without glue. ${ }^{\circ} F_{\mathrm{p}}$ values at each $P_{\mathrm{p}}$ of PTFE/PDMS laminated sheets irradiated of 0.04 to $0.43 \mathrm{MGy}$ at both 77 and $298 \mathrm{~K}$ exceed the corresponding values of the untreated samples. Although $298 \mathrm{~K}-\mathrm{HLEBI}$ with $0.04 \mathrm{MGy}$ improves ${ }^{\circ} F_{\mathrm{p}}$ value at low $P_{\mathrm{p}}(0.06)$, $77 \mathrm{~K}-\mathrm{HLEBI}$ didn't improve it. On the contrary, the $77 \mathrm{~K}-\mathrm{HLEBI}$ with $0.22 \mathrm{MGy}$ apparently enhanced the ${ }^{\circ} F_{\mathrm{p}}$ at low- $P_{\mathrm{p}}$ of 0.06 . It is higher than that of $298 \mathrm{~K}$-HLEBI with $0.22 \mathrm{MGy}$. Furthermore, the operation dose range at high ${ }^{\circ} F_{\mathrm{p}}$ value of more than $1.5 \mathrm{Nm}^{-1}$ at low $P_{\mathrm{p}}(0.06)$ at $77 \mathrm{~K}$, indicator of high industrial reliability of production process, was $0.33 \mathrm{MGy}$, which was more than 3.7 times broader than that at $298 \mathrm{~K}$. Based on the 3-parameter Weibull equation, the lowest ${ }^{\circ} F_{\mathrm{p}}$ value at $P_{\mathrm{p}}$ of zero $\left(F_{\mathrm{s}}\right)$ could be estimated. The $0.22 \mathrm{MGy}-\mathrm{HLEBI}$ at $77 \mathrm{~K}$ apparently improves the $F_{\mathrm{s}}$, which was higher than that $0.22 \mathrm{MGy}-\mathrm{HLEBI}$ at $298 \mathrm{~K}$. Decreasing the irradiation temperature from 298 to $77 \mathrm{~K}$ controlled the rapid adhesion and rapid decay of adhesion at low- $P_{\mathrm{p}}$, which were mainly caused by the low forming ability of dangling bonds induced by strong apparent bonding force, which is related to decreasing atoms vibration energy. Since the $0.22 \mathrm{MGy}-\mathrm{HLEBI}$ at $77 \mathrm{~K}$ controlled the recovery of dangling bonds and generated the chemical bonds, the strong adhesive force of PTFE/PDMS treated by $0.22 \mathrm{MGy}-\mathrm{HLEBI}$ at $77 \mathrm{~K}$ could be explained. Therefore, HLEBI under liquid nitrogen was useful tool for quick strong PTFE/PDMS lamination with sterilization for bio-adaptable application. [doi:10.2320/matertrans.MAW201416]
\end{abstract}

(Received April 18, 2014; Accepted August 8, 2014; Published October 3, 2014)

Keywords: adhesion, electron beam, polytetrafluoroethylene (PTFE), polydimethylsiloxane (PDMS), low temperature

\section{Introduction}

Composite polymers have been prepared for numerous biomedical applications by laminating them with heating and glue. ${ }^{1,2)}$ However, these methods often degrade the adhesive strength and chemical properties, thereby affecting human health. ${ }^{3)}$ Development of rapid adhesion without heating and glue would remedy this. To solve the problem, the development of rapid and safe adhesion method between Polytetrafluoroethylene (PTFE) and Polydimethylsiloxane (PDMS) sheets has been expected. PTFE exhibits high wear resistance as well as high strength and fracture toughness. It can be applied to artificial blood vessels. ${ }^{4}$ PDMS exhibits high transparency and bio-adaptability and has been mainly applied to contact lenze. ${ }^{5)}$ In addition, since the PDMS also shows self-adhesive, ${ }^{3)}$ it can be expected to apply to wrapping the bio-medical sensors.

Homogeneous low energy electron beam irradiation (HLEBI) improves the mist resistance and wetting of inorganic materials, ${ }^{6}$ ) and increases polymer adhering to glass fibers raising impact strength in GFRP. ${ }^{7)}$ Although the large irradiation dose of HLEBI apparently decays as usual radiation damage, small dose often improves the strength of the polymers of polycarbonate and epoxy resin. ${ }^{8,9)}$ HLEBI cut the chemical bonds and generated active terminated atoms with dangling bonds in polymers. ${ }^{10)}$ Dangling bonds enhance surface energy, which is probably caused by chemical bonds for joining the different polymers for PTFE/PDMS at weak-linked polymers near the PTFE/ PDMS interface. ${ }^{10)}$

In addition, treatment time of HLEBI-sterilization is only a few seconds, although sterilizing with ultraviolet light

*Graduate Student, Tokai University irradiation requires a few hours. ${ }^{11)}$ Thus, HLEBI is expected to be an excellent method for not only gluing different polymers without volatilization, but also simultaneously sterilizing them for biomedical applications.

In order to enhance the HLEBI effects on adhesive force, the heating by hot-press after HLEBI was also used to succeed in additive improvement in adhesive force for PTFE/PU and Al/PU. ${ }^{12,13)}$

On the other hand, the cooling is also useful tool to improve the adhesive force. The annihilation of active terminated atoms with dangling bonds generally induces partly occurs at room temperature because of heating recovery. When HLEBI is performed at low temperature, it may control the annihilation and may enhance the probability of the chemical bonds at each weak-linked polymer. It also improves the adhesive force.

Therefore, the effects of HLEBI at $77 \mathrm{~K}$ on peeling resistance of laminated sheet of PTFE and PDMS have been investigated.

\section{Experimental Procedure}

\subsection{Preparation of PTFE/PDMS laminated film}

Composite sheets were constructed with PTFE $(10 \mathrm{~mm} \times 40 \mathrm{~mm} \times 0.050 \mathrm{~mm}$, Skived tape MSF-100, Chukoh chemical industries Co. Ltd., Japan) and PDMS $(10 \mathrm{~mm} \times 40 \mathrm{~mm} \times 0.070 \mathrm{~mm}$, DOW CORNING TORAY SILPOT 184 W/C, Dow Corning Toray Co. Ltd., Japan). Although the PDMS films had been formed by solvent casting method of the spin coating, the PDMS films were prepared by solvent casting method of Doctor Blade with high productivity. ${ }^{14)}$ The glass transition temperatures $\left(T_{\mathrm{g}}\right)$ of PTFE and PDMS are 399 and $150 \mathrm{~K}$, respectively. ${ }^{15)}$ 
PTFE

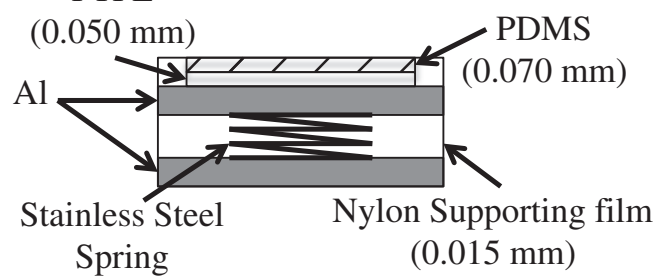

Fig. 1 Schematic diagram of PTFE/PDMS laminated sheet loaded to $80 \mathrm{kPa}$ during irradiation.

\subsection{Homogeneous irradiation of electron beam}

As illustrated in Fig. 1, a jig constructed of a central stainless steel spring between two urethane rubber supporting bases is employed. The 2-layer laminate sample was assembled on the jig: one $0.05 \mathrm{~mm}$ thick PTFE layer, followed by one $0.07 \mathrm{~mm}$ thick PDMS layer, on top of which was placed a $0.015 \mathrm{~mm}$ thick supporting film. Since the HLEBI first penetrated the PDMS layer, followed by the PTFE layer we refereed to the samples as PTFE/PDMS.

To obtain high reproducibility of peeling strength results, compressive stress of more than $80 \mathrm{kPa}$ was loaded for more than $1.0 \mathrm{~h}^{10,12,13)}$ Since no peeling force was observed at the interface between the back surface of PTFE or PDMS layer and the nylon 6 supporting film and in the jig, it was easy to remove the supporting film after irradiation. The sample at the outer surface of the nylon film was homogeneously irradiated in the jig (Fig. 1) by an electron-curtain processor (Type CB175/15/180L, Energy Science Inc., Woburn, MA, Iwasaki Electric Group Co., Ltd., Tokyo). ${ }^{10,12,13,16)}$ The samples are treated at low temperature of $77 \mathrm{~K}$ and room temperature of $298 \mathrm{~K}$ on $\mathrm{Al}$ block with and without dipping liquid nitrogen in Al plate. The level of liquid nitrogen is approximately at the interface between sample and Al block to maintain the constants of irradiation potential and dose because of protecting the liquid covering. The samples were homogeneously irradiated with an electron beam through a titanium window attached to a $0.24 \mathrm{~m}$-diameter vacuum chamber. A tungsten filament in a vacuum was used to generate the electron beam with an electric voltage of $0.17 \mathrm{MeV}$ and an irradiating current of $2.0 \mathrm{~mA}$. To prevent oxidation, the samples were kept in a nitrogen atmosphere of $0.10 \mathrm{MPa}$ with a residual oxygen concentration of less than $0.040 \%$. The flow rate of the nitrogen gas was $1.5 \mathrm{~m}^{3} / \mathrm{Ms}$ (L/s).

Given the densities $(\rho)$ were $2.1 \mathrm{Mg} \cdot \mathrm{m}^{-3}\left(\mathrm{~g} \cdot \mathrm{cm}^{-3}\right)$ for PTFE and $0.97 \mathrm{Mg} \cdot \mathrm{m}^{-3}\left(\mathrm{~g} \cdot \mathrm{cm}^{-3}\right)$ for PDMS, the penetration depth $\left(D_{\text {th }}\right)$ values of $0.105 \mathrm{~mm}$ for PTFE and $0.256 \mathrm{~mm}$ for PDMS were estimated by assumptions of Christenhusz and Reimer, respectively. ${ }^{17)}$ In addition, the $D_{\text {th }}$ values of PTFE $(0.152 \mathrm{~mm})$ and PDMS $(0.38 \mathrm{~mm})$ were also calculated by the assumptions of Libby. ${ }^{18)}$ Namely, the effective depth of homogeneous irradiation was $0.317 \pm 0.061 \mathrm{~mm}$. Consequently, since the irradiated thickness of laminated composites with PTFE film $(50 \mu \mathrm{m}$ thickness $)$ and PDMS film (70 $\mu \mathrm{m}$ thickness) was $120 \mu \mathrm{m}$, the adhesive interface is perfectly irradiated throughout their thicknesses.

\subsection{T-peeling test}

Composite samples after removing the $15 \mu \mathrm{m}$ thick nylon
6 supporting film were prepared for the T-peeling test to evaluate the influence of HLEBI on the mean adhesive force of peeling resistance $\left({ }^{\circ} F_{\mathrm{p}}\right)$. The peeling adhesive force $\left(F_{\mathrm{p}}\right)$ and its peeling distance $\left(d_{\mathrm{p}}\right)$ were obtained by the peeling test, which was performed by using a micro-load tensile tester (F-S Master-1K-2N, IMADA Co. Ltd., Japan) with a strain rate of $10 \mathrm{~mm} / \mathrm{min} .{ }^{10,12,13)}$ Since the unit of the $F_{\mathrm{p}}$ was $\mathrm{N} \mathrm{m}^{-1}$, the ${ }^{\circ} F_{\mathrm{p}}$ was used instead of the adhesive strength, whose units should be $\mathrm{N} \mathrm{m}^{-2}$. The sample condition of tensile test was as follows.

(1) The vertical length from the peeling contact point to the end of the sample was $5 \mathrm{~mm}$.

(2) The $F_{\mathrm{p}}$ was determined by using micro-load tensile tester. The ${ }^{\circ} F_{\mathrm{p}}$ was estimated by the peeling load and experimental peeling width and length of 10 and $30 \mathrm{~mm}$, respectively. The initial distance before peeling $\left(d_{\mathrm{i}}\right)$ was defined at the start point of peeling force, which corresponds to the start point of the first relaxation. The $d_{\mathrm{i}}$ value is $\sim 1 \mathrm{~mm}$.

\subsection{Electron spin resonance (ESR) and X-ray photo- electron spectrometer (XPS) measurements}

Dangling bond density was measured by electron spin resonance spectrometer (ESR: JES-FA200, JEOL Ltd., Tokyo) to obtain more precise information on atomic-scale structural changes in the polymers. ${ }^{7,10,19)}$ The microwave frequency used in the ESR analysis was in the X-band at $9.45 \pm 0.05 \mathrm{GHz}$ with a field modulation of $0.10 \mathrm{MHz}$. The microwave power was $1.0 \mathrm{~mW}$. The magnetic field was varied from 317.0 to $327.0 \mathrm{mT}$.

The PTFE is composed of elements F and C, whereas the PDMS is composed of $\mathrm{C}, \mathrm{H}, \mathrm{Si}$ and O. Fluorine (1s) signals from the peeled PDMS surface, carbon (1s), silicon (2p) and oxygen (1s) signals from the peeled PTFE were detected by X-ray photoelectron spectrometer (XPS: Quantum 2000, ULVAC Co., JAPAN) ${ }^{10)}$ surface analysis of PTFE/PDMS laminated films with and without applying HLEBI at 77 and $298 \mathrm{~K}$.

\section{Results}

\subsection{Peeling load $\left(L_{\mathrm{p}}\right)$ - peeling distance $\left(d_{\mathrm{p}}\right)$ curve}

Although the large adhesive load of peeling resistance has never been measured before irradiation, the laminated sheets constructed with PTFE and PDMS have been prepared before and after room and low temperature HLEBI. HLEBI under 77 and $298 \mathrm{~K}$ laminates the PTFE with the PDMS films. Figure 2 depicts the peeling load $\left(L_{\mathrm{p}}\right)$ - peeling distance $\left(d_{\mathrm{p}}\right)$ curves of the PTFE/PDMS laminated sheets before and after room and low temperature HLEBI at $0.22 \mathrm{MGy}$. When the mean adhesive force of peeling resistance $\left({ }^{\circ} F_{\mathrm{p}}\right)$ is defined from 10 to $30 \mathrm{~mm},{ }^{\circ} F_{\mathrm{p}}$ values of PTFE/PDMS before and after HLEBI under 77 and $298 \mathrm{~K}$ are defined and firstly detected, quantitatively.

\subsection{Mean adhesive force of peeling resistance $\left({ }^{\circ} F_{\mathrm{p}}\right)$}

The accumulated probability $(P)$ of Median Rank meth$\mathrm{od}^{20)}$ is one of convenient ways to analyze the mechanical probabilities of adhesive strength, ${ }^{16)}$ adhesive peeling resistance $^{10)}$ and elasticity, ${ }^{21)}$ as well as strength and impact 


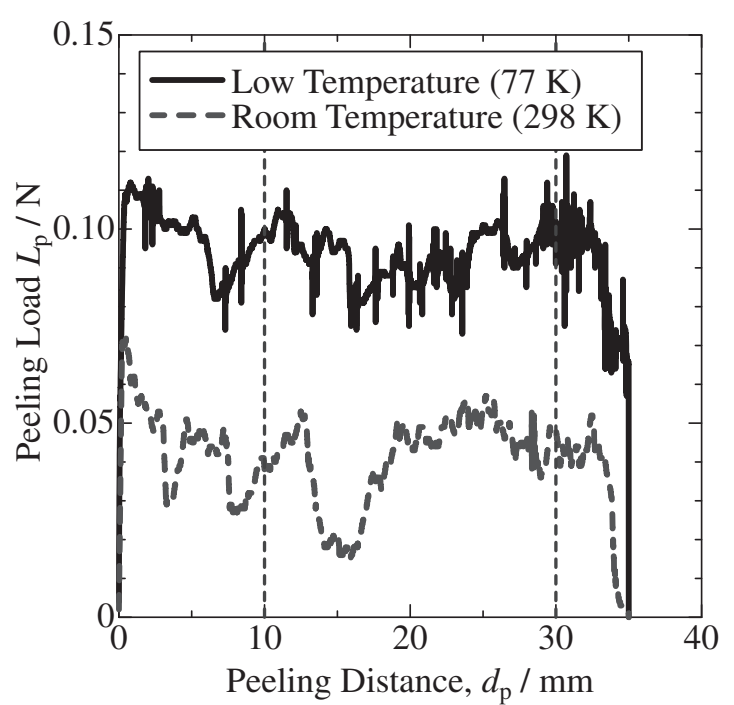

Fig. 2 Peeling load $\left(L_{\mathrm{p}}\right)$ - peeling distance $\left(d_{\mathrm{p}}\right)$ curves of PTFE/PDMS laminated sheets after $0.22 \mathrm{MGy}-\mathrm{HLEBI}$ at 77 and $298 \mathrm{~K}$ at $P_{\mathrm{p}}$ of 0.50 .

value on fracture. ${ }^{7,22-25)}$ This method is useful to evaluate the effects of process, precisely. Evaluating the accumulative probability of peeling $\left(P_{\mathrm{p}}\right)$ is also the convenient method of quantitative analyzing experiment values relating to peeling resistance. ${ }^{10)}$ It is expressed by the following equation.

$$
P_{\mathrm{p}}=(I-0.3) /(n+0.4)
$$

Here, $n$ and $I$ are the total number of samples $(n=11)$ and order of peeling of each sample $(0 \leqq I \leqq 11)$, respectively. When the $I$ values are 1,6 , and 11 , the $P_{\mathrm{p}}$ values are 0.06 , 0.50 and 0.94 , respectively.

Although the large dose of HLEBI apparently decays as usual radiation damage, small dose from 0.04 to $0.43 \mathrm{MGy}$ improves the ${ }^{\mathrm{o}} F_{\mathrm{p}}$ values of the PTFE/PDMS laminated sheets. Figure 3 plots the relationships between ${ }^{\circ} F_{\mathrm{p}}$ and the $P_{\mathrm{p}}$ of PTFE/PDMS laminated sheets before and after HLEBI under (a) low and (b) room temperatures, together with the lowest adhesive force estimated (๑): $F_{\mathrm{s}}={ }^{\circ} F_{\mathrm{p}}$ at $P_{\mathrm{p}}=0$ ). Small ${ }^{\circ} F_{\mathrm{p}}$ values of PTFE/PDMS laminated sheets untreated at room temperature of $298 \mathrm{~K}$ can be obtained, although adhesion cannot be detected for untreated samples at $77 \mathrm{~K}$. ${ }^{\circ} F_{\mathrm{p}}$ values at each $P_{\mathrm{p}}$ of PTFE/PDMS laminated sheets irradiated of 0.04 to $0.43 \mathrm{MGy}$ at 77 and $298 \mathrm{~K}$ always exceed the corresponding values of the untreated samples.

Figure 4 depicts the changes in ${ }^{\circ} F_{\mathrm{p}}\left(\mathrm{N} \mathrm{m}^{-1}\right)$ at each $P_{\mathrm{p}}$ of 0.06 and 0.50 of PTFE/PDMS laminated sheets before and after HLEBI under (a) low and (b) room temperatures, together with the lowest adhesive force estimated (๑: $F_{\mathrm{s}}=$ ${ }^{\circ} F_{\mathrm{p}}$ at $\left.P_{\mathrm{p}}=0\right)$. HLEBI with small irradiation dose of $0.04 \mathrm{MGy}$ at both 77 and $297 \mathrm{~K}$ improves ${ }^{\circ} F_{\mathrm{p}}$ values $(4.68$ and $\left.4.89 \mathrm{~N} \mathrm{~m}^{-1}\right)$ at mid- $P_{\mathrm{p}}(0.50)$, respectively. The ${ }^{\circ} F_{\mathrm{p}}$ values at low- $P_{\mathrm{p}}(0.06)$ is zero $\mathrm{Nm}^{-1}$ for small dose of $0.04 \mathrm{MGy}$ at $77 \mathrm{~K}$, although $0.04 \mathrm{MGy}-\mathrm{HLEBI}$ at $298 \mathrm{~K}$ also enhances the ${ }^{\circ} F_{\mathrm{p}}$ values up to $3.00 \mathrm{~N} \mathrm{~m}^{-1}$ at low- $P_{\mathrm{p}}(0.06)$. Namely, although $298 \mathrm{~K}$-HLEBI with $0.04 \mathrm{MGy}$ improves ${ }^{\mathrm{o}} F_{\mathrm{p}}$ value at low $P_{\mathrm{p}}(0.06), 77 \mathrm{~K}-\mathrm{HLEBI}$ didn't improve it. Decreasing the irradiation temperature controls the rapid adhesion.

On the contrary, the $77 \mathrm{~K}-\mathrm{HLEBI}$ with $0.22 \mathrm{MGy}$ apparently enhanced the ${ }^{\circ} F_{\mathrm{p}}$ at low- $P_{\mathrm{p}}$ of 0.06 . It is higher than that of $298 \mathrm{~K}$-HLEBI with $0.22 \mathrm{MGy}$. The ${ }^{\circ} F_{\mathrm{p}}$ value $(2.98$ and $\left.4.84 \mathrm{~N} \mathrm{~m}^{-1}\right)$ at low and mid- $P_{\mathrm{p}}(0.06$ and 0.50$)$ of $0.22 \mathrm{MGy}-\mathrm{HLEBI}$ at $77 \mathrm{~K}$ under liquid nitrogen was more than 2.4 and 1.2 times larger than that $\left(1.26\right.$ and $\left.4.10 \mathrm{~N} \mathrm{~m}^{-1}\right)$ at room temperature of $298 \mathrm{~K}$.

Furthermore, the operation dose range at high ${ }^{\circ} F_{\mathrm{p}}$ value of more than $1.5 \mathrm{~N} \mathrm{~m}^{-1}$ at low $P_{\mathrm{p}}(0.06)$ at $77 \mathrm{~K}$ under liquid nitrogen was $0.30 \mathrm{MGy}$ from 0.13 to $0.43 \mathrm{MGy}$. The doze range is more than 3.7 times broader than that $(0.13 \mathrm{MGy})$ from 0.04 to $0.13 \mathrm{MGy}$ at room temperature of $298 \mathrm{~K}$. The $0.22 \mathrm{MGy}$ HLEBI process at $77 \mathrm{~K}$ with the large dose range (0.30 MGy) enhances the high industrial reliability of production process.

\section{( b ) 298 K-HLEBI}

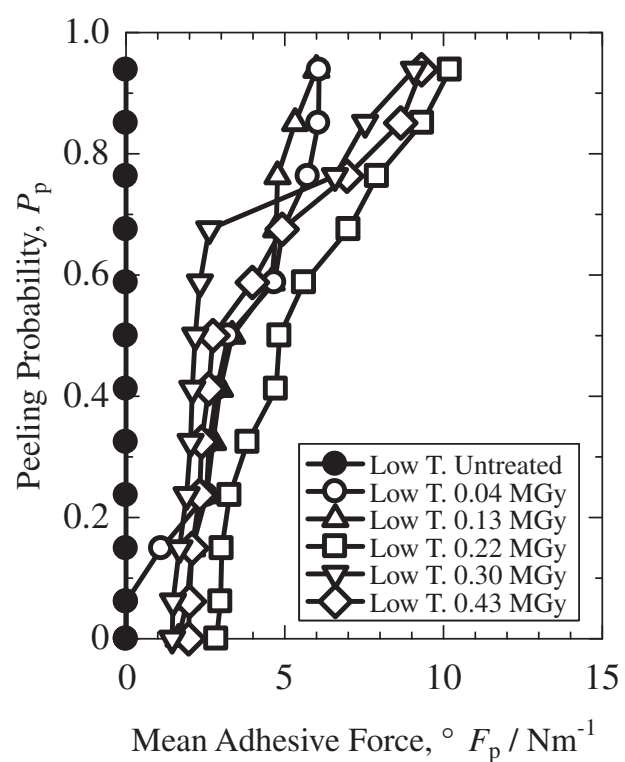

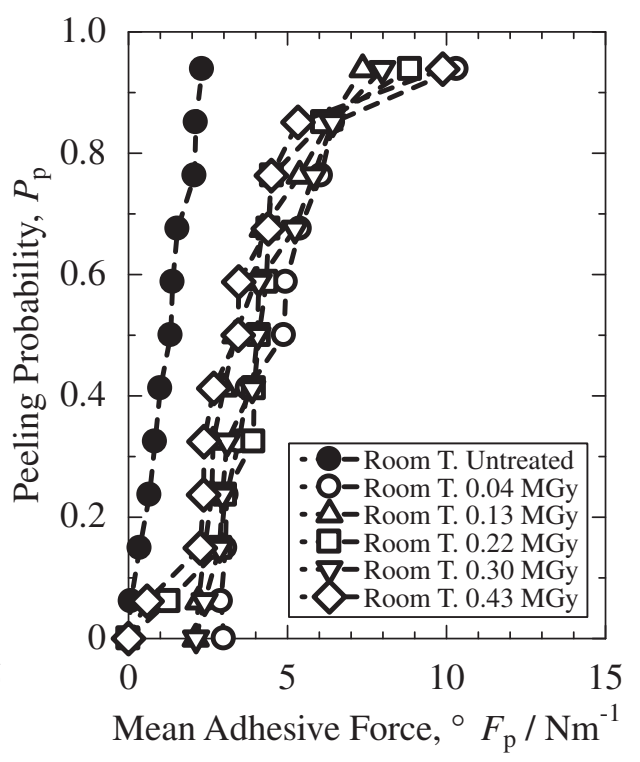

Fig. 3 Relationships between ${ }^{\circ} F_{\mathrm{p}}$ and the accumulative probability of peeling $\left(P_{\mathrm{p}}\right)$ of PTFE/PDMS laminated sheets untreated and treated by HLEBI at (a) low and (b) room temperatures, together with the lowest adhesive force estimated (@): $F_{\mathrm{s}}={ }^{\circ} F_{\mathrm{p}}$ at $\left.P_{\mathrm{p}}=0\right)$. 
( a ) 77 K-HLEBI

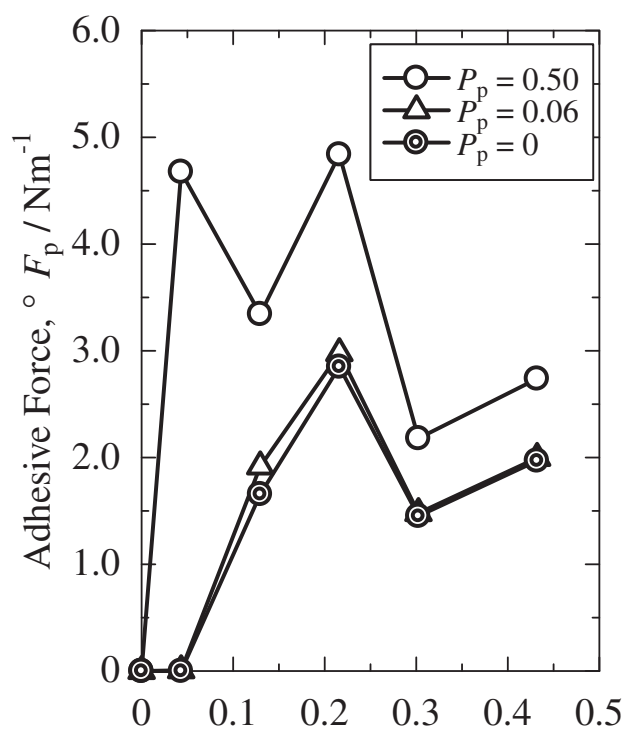

EB Irradiation Dose, $D$ / MGy
( b ) 298 K-HLEBI

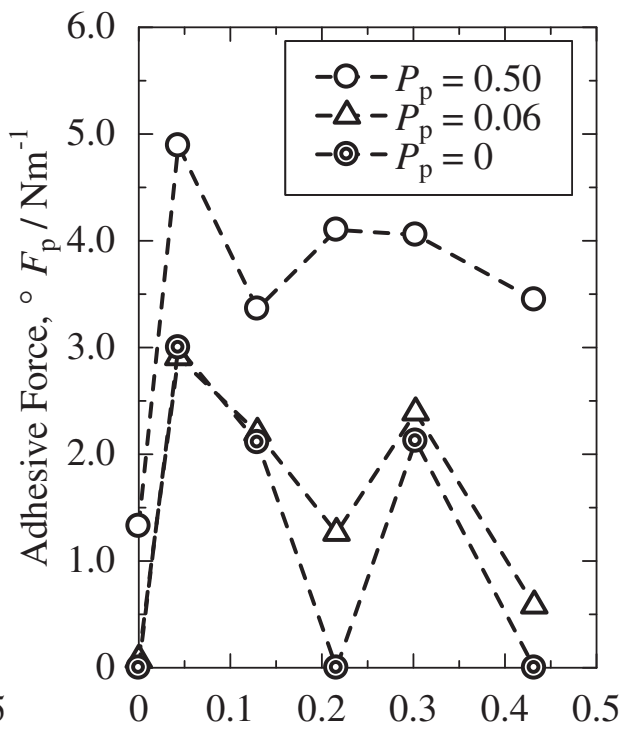

EB Irradiation Dose, $D$ / MGy

Fig. 4 Changes in ${ }^{\circ} F_{\mathrm{p}}$ at each $P_{\mathrm{p}}$ of 0.06 and 0.50 of PTFE/PDMS laminated sheets untreated and treated by HLEBI under (a) low and

(b) room temperatures HLEBI, together with the lowest adhesive force (@): $F_{\mathrm{s}}={ }^{\circ} F_{\mathrm{p}}$ at $P_{\mathrm{p}}=0$ ).

\section{Discussion}

\subsection{The lowest adhesive force}

In order to obtain the safety design, the lowest ${ }^{\circ} F_{\mathrm{p}}$ value at $P_{\mathrm{p}}$ of zero $\left(F_{\mathrm{s}}\right)$ assumes to be attained from the adaptable relationship of the 3-parameter Weibull equation iterating to the high correlation coefficient $(F)$. The $P_{\mathrm{p}}$ depends on the risk of rupture $\left(\left[{ }^{\circ} F_{\mathrm{p}}-F_{\mathrm{s}}\right] / F_{\mathrm{III}}\right) \cdot{ }^{10,21-26)}$

$$
P_{\mathrm{p}}=1-\exp \left[-\left(\left[{ }^{\mathrm{o}} F_{\mathrm{p}}-F_{\mathrm{s}}\right] / F_{\mathrm{III}}\right)^{m}\right]
$$

The $F_{\text {III }}$ value is the ${ }^{\circ} F_{\mathrm{p}}$ value, when the term $\ln \left[-\ln \left(1-P_{\mathrm{p}}\right)\right]$ is zero. When $P_{\mathrm{p}}=0$, the required ${ }^{\circ} F_{\mathrm{p}}$ value to evaluate new structural materials is defined as the

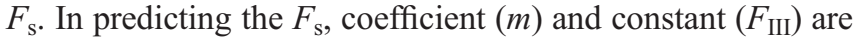
the key parameters. Figures 5 (a) and (b) plots changes in correlation coefficient $(f)$ with respect to the potential ${ }^{\circ} F_{\mathrm{s}}$ value $\left({ }^{e} F_{\mathrm{s}}\right)$ estimated from eq. (2). The ${ }^{\circ} F_{\mathrm{s}}$ value is the ${ }^{e} F_{\mathrm{s}}$ value at the maximum $F$ value. Figure 5 (c) and (d) illustrates the linear relationships between $\ln \left({ }^{\circ} F_{\mathrm{p}}-F_{\mathrm{s}}\right)$ and $\ln \left[-\ln \left(1-P_{\mathrm{p}}\right)\right]$ for PTFE/PDMS laminated sheets before and after low and room temperature HLEBI. The values of $F_{\text {III }}$ and $m$ are determined by the least-squares method. The $m$ value is estimated by the slope of the relationship when ${ }^{e} F_{\mathrm{s}}=F_{\mathrm{s}}$.

Figure 4 also depicts the changes in the lowest adhesive force (๑: $F_{\mathrm{s}}={ }^{\circ} F_{\mathrm{p}}$ at $\left.P_{\mathrm{p}}=0\right)$, together with ${ }^{\circ} F_{\mathrm{p}}\left(\mathrm{N} \mathrm{m}^{-1}\right)$ at each $P_{\mathrm{p}}$ of 0.06 and 0.50 of PTFE/PDMS laminated sheets before and after HLEBI under (a) low and (b) room temperatures, respectively. The estimated ${ }^{\circ} F_{\mathrm{p}}$ value $(2.85$ $\mathrm{N} \mathrm{m}^{-1}$ ) at zero of $P_{\mathrm{p}}$ of $0.22 \mathrm{MGy}-\mathrm{HLEBI}$ at $77 \mathrm{~K}$ under liquid nitrogen, which is slightly smaller than the experimental one $\left(2.98 \mathrm{~N} \mathrm{~m}^{-1}\right)$ at small $P_{\mathrm{p}}(0.06)$, is remarkably higher than estimated ${ }^{\circ} F_{\mathrm{p}}$ value at room temperature of $298 \mathrm{~K}$. The 0.22 MGy-HLEBI under liquid nitrogen apparently improves the safety adhesive force.

\subsection{Adhesion with dangling bond formation}

Although the large dose of HLEBI apparently decays as usual radiation damage, small dose from 0.04 to $0.43 \mathrm{MGy}$ improves the ${ }^{\circ} F_{\mathrm{p}}$ values of the $\mathrm{PTFE} / \mathrm{PDMS}$ laminated sheets. Although remarkable electron spin resonance (ESR) signals, indicating dangling bond formation, could not be detected in either the untreated PTFE or PDMS, the ESR signals of PTFE treated by 298 K-HLEBI could be detected. ${ }^{10)}$ Increasing the density of active terminated atoms with dangling bonds enlarges the free volume in polymers. ${ }^{27)}$ Since HLEBI up to $0.43 \mathrm{MGy}$ enhances the intensity of the ESR signals in the PTFE, it gradually enhances the density of dangling bonds. On the other hand, HLEBI up to $0.04 \mathrm{MGy}$ slightly enhances the intensity in the PDMS. ${ }^{10)}$ Since the glass transition temperature $\left(T_{\mathrm{g}}\right)$ of PDMS is below room temperature, the recovery easily occurs, resulting in weak in PDMS.

Although the recovery partly occurs at room temperature, HLEBI cut the chemical bonds and generated active terminated atoms with dangling bonds in PTFE and PDMS polymers. It is possible to induce the chemical bonding at not only interface, but also cross-linked polymers. The annihilation of active terminated atoms with dangling bonds of polymers generally induces partly occurs at room temperature by heating recovery. When HLEBI is performed at low temperature, it probably controls the annihilation and enhances the probability of the chemical bonds at each cross-linked polymer. Thus, it also improves the adhesive force.

\subsection{Concepts of chemical bonds between terminated groups of cross-linked PTFE and PDMS polymers with dangling bonds}

Figure 6 illustrates the constitutional formula of chemical bonds of $[\mathrm{PTFE}]_{n}-[\mathrm{PDMS}]_{m}$ and $[\mathrm{PDMS}]_{m}-[\mathrm{PTFE}]_{n}$ of crosslinking zone of PTFE/PDMS laminated composites sheet. 


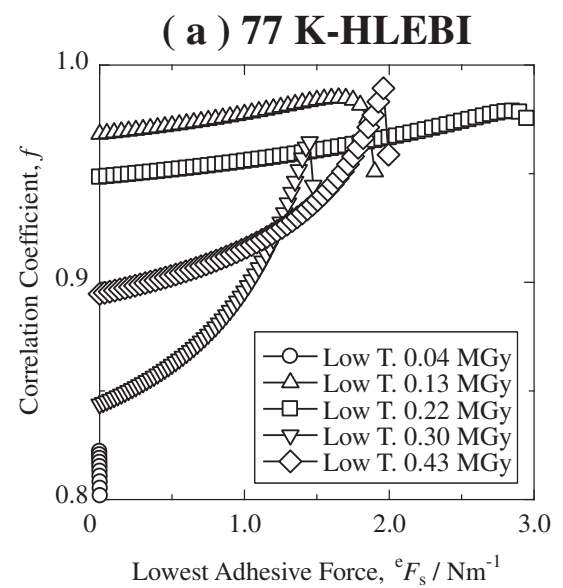

( c ) 77 K-HLEBI

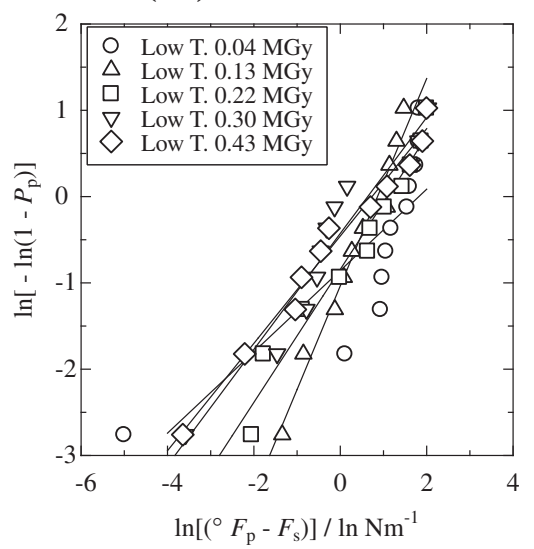

( b ) 298 K-HLEBI

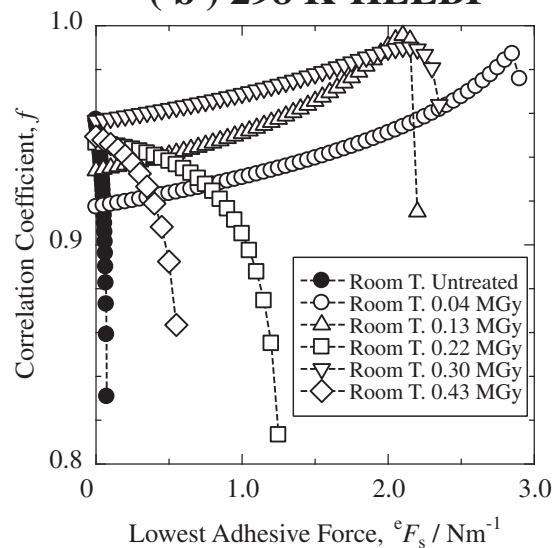

( d ) 298 K-HLEBI

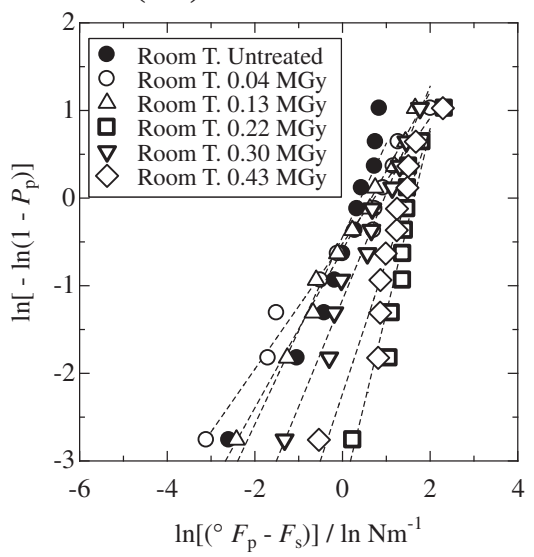

Fig. 5 Changes in correlation coefficient $(f)$ of eq. (2) against the potential value ( $\left.{ }^{\mathrm{e}} F_{\mathrm{s}}\right)((\mathrm{a})$, (b)), and liner relationships between $\ln \left({ }^{\mathrm{o}} F_{\mathrm{p}}-F_{\mathrm{s}}\right)$ and $\ln \left[-\ln \left(1-P_{\mathrm{p}}\right)\right]((\mathrm{c}),(\mathrm{d}))$ for PTFE/PDMS laminated sheets untreated and treated by HLEBI at 77 ((a), (c)) and $298 \mathrm{~K}$ ((b), (d)).

(a) $[\text { PTFE }]_{n}-[\text { PDMS }]_{\mathrm{m}}$

(b) $[\text { PDMS }]_{\mathrm{m}}-[\mathrm{PTFE}]_{\mathrm{n}}$

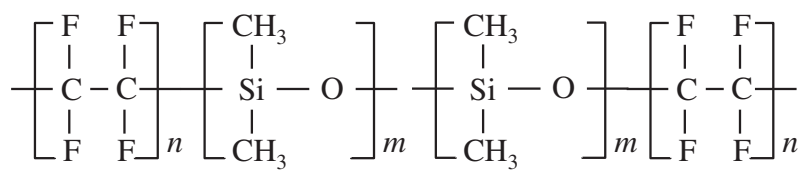

Fig. 6 Constitutional formula of chemical bonds of $[\mathrm{PTFE}]_{n}-[\mathrm{PDMS}]_{m}$ and $[\mathrm{PDMS}]_{m}-[\mathrm{PTFE}]_{n}$ of cross-linking zone of PTFE/PDMS laminated composites sheet.

When the cross-linking occurs at interface between PTFE and PDMS samples, chemical atomic bonds between active terminated silicon (or oxygen) atom in cross-linked PDMS polymers and active terminated carbon atom in cross-linked PTFE polymers probably attribute to the HLEBI-adhesion.

\subsection{Effects of decreasing the irradiation temperature on adhesive force and density of dangling bonds evaluated by ESR}

Figure 7 shows ESR signals related to dangling bonds of pealed PTFE and PDMS sheets before and after HLEBI with 0.04 and $0.22 \mathrm{MGy}$ at 77 and $298 \mathrm{~K}$, respectively. Increasing HLEBI dose enhances the intensity of ESR signal of PTFE. Dangling bonds relate to the interatomic bonding strongly related to atoms vibration energy. Thus, Since ESR intensity of PTFE irradiated at $298 \mathrm{~K}$ is higher than that at $77 \mathrm{~K}$, decreasing irradiation temperature from 298 to $77 \mathrm{~K}$ suppresses the formation of dangling bonds for PTFE polymers.

When the experimental adhesive force at low $P_{\mathrm{p}}$ of 0.06 is extremely low near zero (see Fig. 4), when remarkable ESR signals cannot be observed, as shown in Fig. 7(a) and (b).

On the other hand, as the adhesion decay occurs at $298 \mathrm{~K}$ $0.22 \mathrm{MGy}$, radiation damage apparently occurs at its ESR intensity of the PTFE.

Since the highest value of adhesive force at low $P_{\mathrm{p}}$ of 0.06 is found at $298 \mathrm{~K}-0.04 \mathrm{MGy}$ and $77 \mathrm{~K}-0.22 \mathrm{MGy}$, the density of dangling bonds is optimum to improve the adhesion force, as shown in Fig. 7(a) and (b).

ESR signals can be detected for PDMS treated by HLEBI at $298 \mathrm{~K}$, although ESR signals cannot be mostly observed at $77 \mathrm{~K}$. Decreasing the irradiation temperature from 298 to $77 \mathrm{~K}$ apparently suppresses the formation of dangling bonds for PDMS polymers, resulting in delay of the radiation damage.

As shown in Fig. 4, decreasing the irradiation temperature from 298 to $77 \mathrm{~K}$ suppresses the not only rapid adhesion $\left({ }^{\circ} F_{\mathrm{p}}\right)$ from zero to $3.00 \mathrm{~N} \mathrm{~m}^{-1}$, but also rapid decay of adhesion $\left({ }^{\circ} F_{\mathrm{p}}\right)$ from 3.00 to less than $1.0 \mathrm{~N} \mathrm{~m}^{-1}$ at low- $P_{\mathrm{p}}$ of 0.06 . Controlling both rapid adhesion and rapid decay of adhesion is mainly caused by suppressing the formation of dangling 
( a ) PTFE at $77 \mathrm{~K}$

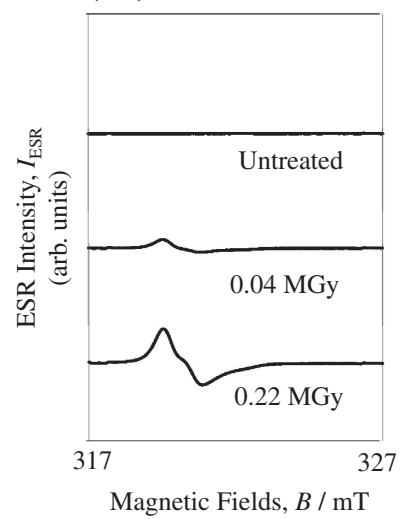

(c) PDMS at $77 \mathrm{~K}$

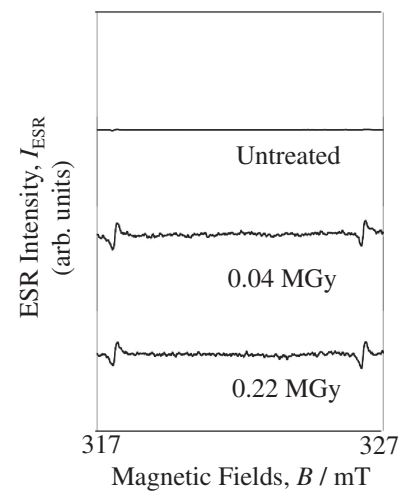

( b ) PTFE at $298 \mathrm{~K}$

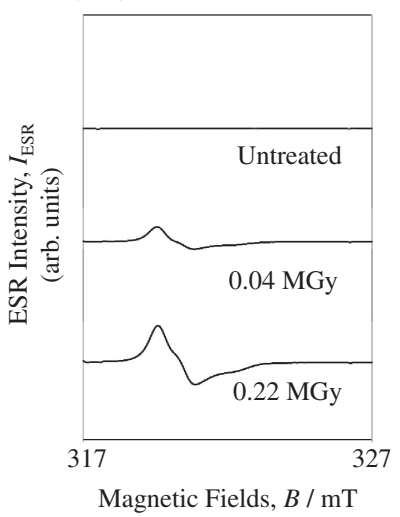

( d ) PDMS at $298 \mathrm{~K}$

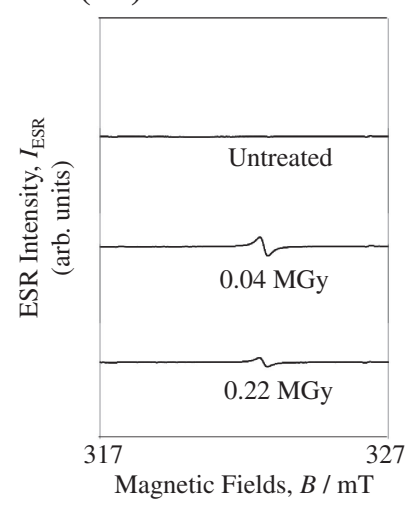

Fig. 7 ESR signals of pealed PTFE and PDMS sheets before and after HLEBI with 0.04 and $0.22 \mathrm{MGy}$ at 77 and $298 \mathrm{~K}$

bonds induced by strong apparent bonding force, which is related to decreasing atoms vibration energy by decreasing the irradiation temperature.

\subsection{Chemical bonds of cross-linking evaluated by XPS}

As shown in Fig. 6, the PTFE is composed of elements of $\mathrm{F}$ and $\mathrm{C}$, whereas the PDMS is composed of elements of $\mathrm{C}$, $\mathrm{H}, \mathrm{Si}$ and O. Figure 8(a) illustrates fluorine (1s) signals from the peeled PDMS surface by XPS surface analysis of PTFE/ PDMS laminated films with and without applying 0.22 MGyHLEBI at 77 and $298 \mathrm{~K}$, when the low $P_{\mathrm{p}}$ value is 0.06 .

Based on the results of XPS surface analysis for PTFE/ PDMS laminated sheets after 0.22 MGy-HLEBI under 77 and $298 \mathrm{~K}$, fluorine is found in the PDMS side peeled surface. No signals can be observed in the samples untreated and treated by $0.04 \mathrm{MGy}-\mathrm{HLEBI}$ at $77 \mathrm{~K}$. On the contrary, the XPS signals observed exhibits that the peeling test cuts the crosslinked parts of PTFE molecules including the element F on the PDMS side in the laminated composites sheets treated by $0.04 \mathrm{MGy}$ at $298 \mathrm{~K}$ and $0.22 \mathrm{MGy}$ at 77 and $298 \mathrm{~K}$.

The XPS signal intensity of PTFE/PDMS treated by $0.22 \mathrm{MGy}-\mathrm{HLEBI}$ at $298 \mathrm{~K}$ is much higher than that by $0.22 \mathrm{MGy}-\mathrm{HLEBI}$ at $77 \mathrm{~K}$. The residual amount of PTFE molecules of PTFE/PDMS treated by 0.22 MGy-HLEBI at $298 \mathrm{~K}$ is much larger than that by $0.22 \mathrm{MGy}-\mathrm{HLEBI}$ at $77 \mathrm{~K}$. Since the ${ }^{\mathrm{o}} F_{\mathrm{p}}$ value $\left(2.98 \mathrm{~N} \mathrm{~m}^{-1}\right)$ at low $P_{\mathrm{p}}(0.06)$ of $0.22 \mathrm{MGy}-\mathrm{HLEBI}$ at $77 \mathrm{~K}$ under liquid nitrogen was more than 2.4 times larger than that $\left(1.26 \mathrm{~N} \mathrm{~m}^{-1}\right)$ at room temperature of $298 \mathrm{~K}$, the radiation damage of PTFE molecules of PTFE/PDMS treated by 0.22 MGy-HLEBI at $77 \mathrm{~K}$ should be smaller than that by $0.22 \mathrm{MGy}-\mathrm{HLEBI}$ at $298 \mathrm{~K}$.

Since the adhesive chemical bonding at cross-linking zone near PTFE/PDMS interface is probably lower than the fracture strength between cross-linked PTFE molecules and residual PTFE molecules in PTFE sheet, it can be explained that the high ${ }^{\circ} F_{\mathrm{p}}$ value can be detected of laminated composites sheet treated by $0.04 \mathrm{MGy}-\mathrm{HLEBI}$ at $298 \mathrm{~K}$ and $0.22 \mathrm{MGy}-\mathrm{HLEBI}$ at $77 \mathrm{~K}$.

The strength of PTFE polymers are generally much stronger than that of PDMS. Thus, the dominant factors to adhesion should be the strength of PTFE polymers, rather than that of PDMS. Although the contribution of cross linked PDMS polymers is not so large, the influence of PDMS cross linked polymer on adhesion is investigated. Figure 8(b) illustrates silicon (2p) signals from the peeled PTFE surface by XPS surface analysis of PTFE/PDMS laminated films
(a)Element $F$ in PDMS sheet side at low $P_{p}=0.06$

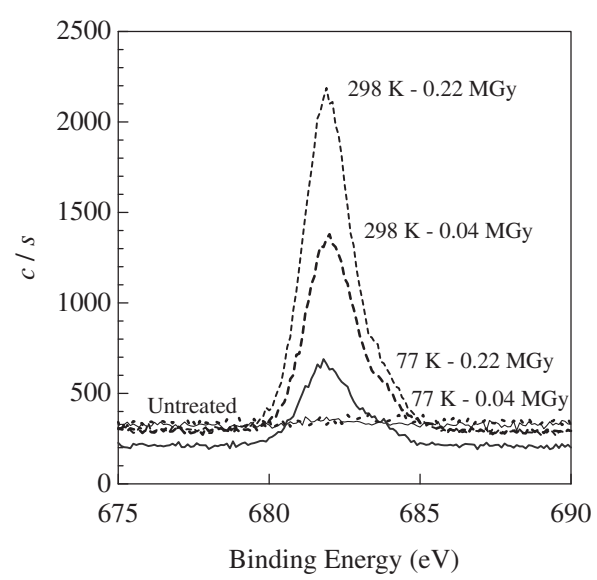

(b)Element Si in PTFE sheet side at low $P_{\mathrm{p}}=0.06$

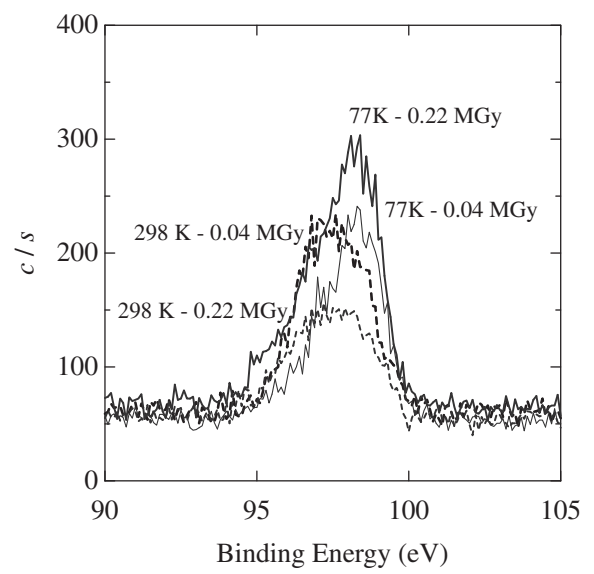

Fig. 8 Fluorine (1s) and silicon (2p) signals on PDMS and PTFE sides from XPS analysis PTFE/PDMS laminated sheets untreated and treated by 0.04 and $0.22 \mathrm{MGy}-\mathrm{HLEBI}$ at low $(77 \mathrm{~K})$ and room temperatures $(298 \mathrm{~K})$, respectively. 
treated by $0.22 \mathrm{MGy}-\mathrm{HLEBI}$ at 77 and $298 \mathrm{~K}$, when the low $P_{\mathrm{p}}$ value is 0.06 . The XPS signals observed exhibit that the peeling test cuts the cross-linked parts of PDMS molecules including the element $\mathrm{Si}$ on the PTFE side in the all laminated composites sheets treated by HLEBI at 77 and $298 \mathrm{~K}$.

The XPS signal intensity of PTFE/PDMS treated by $0.22 \mathrm{MGy}-\mathrm{HLEBI}$ at $77 \mathrm{~K}$ exhibits the highest value, which is 1.25 and 2.5 times higher that that of both $0.04 \mathrm{MGy}-\mathrm{HLEBI}$ at 77 and $298 \mathrm{~K}$ and $0.22 \mathrm{MGy}$ at $298 \mathrm{~K}$. The XPS signal intensity related to residual amount of PDMS molecules with $\mathrm{Si}$ of PTFE/PDMS treated by $0.22 \mathrm{MGy}-\mathrm{HLEBI}$ at $77 \mathrm{~K}$ is 1.25 higher than that by $0.04 \mathrm{MGy}-\mathrm{HLEBI}$ at $298 \mathrm{~K}$. On the contrary, the XPS signal of element F of PTFE molecules in PDMS side in PTFE/PDMS treated by 0.04 MGy-HLEBI at $298 \mathrm{~K}$ is about 4 times higher than that by $0.22 \mathrm{MGy}-\mathrm{HLEBI}$ at $77 \mathrm{~K}$, as shown in Fig. 8(a). Although the ${ }^{\circ} F_{\mathrm{p}}$ value $\left(2.98 \mathrm{~N} \mathrm{~m}^{-1}\right)$ at low $P_{\mathrm{p}}(0.06)$ of $0.22 \mathrm{MGy}-\mathrm{HLEBI}$ at $77 \mathrm{~K}$ and $0.04 \mathrm{MGy}-\mathrm{HLEBI}$ at $298 \mathrm{~K}$ are same to each other, we conclude that the dominant factor of one is different from another.

On the other hand, the XPS signal intensity of Si in PTFE side of PTFE/PDMS treated by $0.04 \mathrm{MGy}$ at $298 \mathrm{~K}$ is about $60 \%$ of that by $0.22 \mathrm{MGy}$ at $77 \mathrm{~K}$, whereas its intensity of $\mathrm{F}$ in strong PTFE molecules in PDMS is too small. Thus, the lowest adhesion force can be explained.

In addition, since the XPS signal intensity of Si in PTFE side of PTFE/PDMS treated by $0.22 \mathrm{MGy}$ at $298 \mathrm{~K}$ is about $30 \%$ of that by $0.22 \mathrm{MGy}$ at $77 \mathrm{~K}$, the decreasing adhesion force can be explained, as shown in Fig. 4.

\subsection{Principle of HLEBI adhesion of PTFE/PDMS}

It is possible that HLEBI cuts the chemical bonds of atoms in monomers, as well as that between monomers.

When HLEBI cuts molecules in both polymers and forms the terminated atoms of $-\mathrm{CH}_{3},-\mathrm{H}$ and $-\mathrm{F}$ with dangling bonds, it cannot attribute to the chemical bond site between cross-linked different molecules.

When HLEBI cuts molecules in both polymers and forms the terminated atoms of $[\mathrm{PTFE}]_{n}-\mathrm{CF}_{2^{-}},-\mathrm{O}-[\mathrm{PDMS}]_{m}$ and $\left.-\mathrm{Si}\left(-\mathrm{CH}_{3}\right)_{2}-[\mathrm{PDMS}]_{m}\right)$ with dangling bonds, it is possible to form the bonding modes of $[\mathrm{PTFE}]_{n}-\mathrm{CF}_{2}-[\mathrm{PDMS}]_{m}$, $[\mathrm{PTFE}]_{n}-\mathrm{O}-[\mathrm{PDMS}]_{m}$ and $[\mathrm{PTFE}]_{n}-\mathrm{Si}\left(-\mathrm{CH}_{3}\right)_{2}-[\mathrm{PDMS}]_{m}$ between cross-linked PTFE and PDMS polymers.

Although the dominant factor of precise bonding mode for adhesion cannot confirmed, chemical bonds between crosslinked PTFE and PDMS polymers should attribute to the HLEBI-adhesion.

\section{Conclusion}

The effects of homogeneous low voltage electron beam irradiation (HLEBI) at $77 \mathrm{~K}$ with sterilization on the adhesive force of peeling $\left({ }^{\circ} F_{\mathrm{p}}\right)$ of laminated PTFE/PDMS sheets constructed with polytetrafluoroethylene (PTFE) and polydimethylsiloxane (PDMS) were investigated without glue.

(1) The relationships between ${ }^{\mathrm{o}} F_{\mathrm{p}}$ and the accumulative probability of peeling $\left(P_{\mathrm{p}}\right)$ of PTFE/PDMS laminated sheets before and after HLEBI under low and room temperatures were obtained. ${ }^{\circ} F_{\mathrm{p}}$ values at each $P_{\mathrm{p}}$ of
PTFE/PDMS laminated sheets irradiated of 0.04 to 0.43 MGy at both 77 and $298 \mathrm{~K}$ exceed the corresponding values of the untreated samples. Although $298 \mathrm{~K}-$ HLEBI with $0.04 \mathrm{MGy}$ improves ${ }^{\circ} F_{\mathrm{p}}$ value at low $P_{\mathrm{p}}$ (0.06), 77 K-HLEBI didn't improve it. On the contrary, the $77 \mathrm{~K}$-HLEBI with $0.22 \mathrm{MGy}$ apparently enhanced the ${ }^{\circ} F_{\mathrm{p}}$ at low- $P_{\mathrm{p}}$ of 0.06 . It is higher than that of $298 \mathrm{~K}-$ HLEBI with $0.22 \mathrm{MGy}$.

(2) The operation dose range at high ${ }^{\circ} F_{\mathrm{p}}$ value of more than $1.5 \mathrm{~N} \mathrm{~m}^{-1}$ at low $P_{\mathrm{p}}(0.06)$ at $77 \mathrm{~K}$ was $0.30 \mathrm{MGy}$ from 0.13 to $0.43 \mathrm{MGy}$. It was more than 3.7 times broader than that (0.13 MGy) from 0.04 to $0.13 \mathrm{MGy}$ at $298 \mathrm{~K}$. It enhances the high industrial reliability of production process.

(3) Based on the 3-parameter Weibull equation, the lowest ${ }^{\circ} F_{\mathrm{p}}$ value at $P_{\mathrm{p}}$ of zero $\left(F_{\mathrm{s}}\right)$ could be estimated. The $0.22 \mathrm{MGy}-\mathrm{HLEBI}$ at $77 \mathrm{~K}$ apparently improves the safety adhesive force, which is higher than that 0.22 MGy-HLEBI at $298 \mathrm{~K}$.

(4) The X-ray photoelectron spectrometer (XPS) signal intensity of the element F on the PDMS side in PTFE/ PDMS treated by $0.22 \mathrm{MGy}-\mathrm{HLEBI}$ at $298 \mathrm{~K}$ is much higher than that by $0.22 \mathrm{MGy}-\mathrm{HLEBI}$ at $77 \mathrm{~K}$. Since the ${ }^{\circ} F_{\mathrm{p}}$ value $\left(2.98 \mathrm{~N} \mathrm{~m}^{-1}\right)$ at low $P_{\mathrm{p}}(0.06)$ of $0.22 \mathrm{MGy}-$ HLEBI at $77 \mathrm{~K}$ under liquid nitrogen was more than 2.4 times larger than that $\left(1.26 \mathrm{~N} \mathrm{~m}^{-1}\right)$ at room temperature of $298 \mathrm{~K}$, the radiation damage of PTFE molecules of PTFE/PDMS treated by $0.22 \mathrm{MGy}-\mathrm{HLEBI}$ at $77 \mathrm{~K}$ should be smaller than that by $0.22 \mathrm{MGy}-\mathrm{HLEBI}$ at $298 \mathrm{~K}$.

(5) Since the adhesive chemical bonding at cross-linking zone near PTFE/PDMS interface is probably lower than the fracture strength between cross-linked PTFE molecules and residual PTFE molecules in PTFE sheet, it can be explained that the high ${ }^{\circ} F_{\mathrm{p}}$ value can be detected of laminated composites sheet treated by 0.04 MGy-HLEBI at $298 \mathrm{~K}$ and 0.22 MGy-HLEBI at $77 \mathrm{~K}$.

(6) Based on the silicon (2p) signals from the peeled PTFE surface by XPS surface analysis of PTFE/PDMS laminated films with and without applying 0.22 MGyHLEBI at 77 and $298 \mathrm{~K}$, the XPS signal intensity related to residual amount of PDMS molecules of PTFE/PDMS treated by $0.22 \mathrm{MGy}-\mathrm{HLEBI}$ at $77 \mathrm{~K}$ is 1.25 higher than that by $0.04 \mathrm{MGy}-\mathrm{HLEBI}$ at $298 \mathrm{~K}$. On the contrary, the XPS signal of element F of PTFE molecules in PDMS side in PTFE/PDMS treated by $0.04 \mathrm{MGy}-\mathrm{HLEBI}$ at $298 \mathrm{~K}$ is about 4 times higher than that by $0.22 \mathrm{MGy}-\mathrm{HLEBI}$ at $77 \mathrm{~K}$. Although the ${ }^{\circ} F_{\mathrm{p}}$ value $\left(2.98 \mathrm{~N} \mathrm{~m}^{-1}\right)$ at low $P_{\mathrm{p}}(0.06)$ of $0.22 \mathrm{MGy}-$ HLEBI at $77 \mathrm{~K}$ and $0.04 \mathrm{MGy}-\mathrm{HLEBI}$ at $298 \mathrm{~K}$ are same to each other, we conclude that the dominant factor of one is different from another.

\section{Acknowledgements}

The authors thank Prof. Michael C. Faudree and Prof. Akira Tonegawa of Tokai University for their useful help. Our sincere gratitude also goes to Eye Electron Beam Co., Ltd. (Gyoda, Saitama, Japan) for their support with this work. 


\section{REFERENCES}

1) M. Kobayashi: Plastics 41 (1990) 84-89.

2) T. Nakayasu and Y. Oohashi: Technol. Adhes. Seal. 46 (2002) 451456

3) T. Hayashi: J. Japan Weld. Soc. 39 (1990) 141-146.

4) R. Kodama: Zinkouzouki 34 (2005) 147-151.

5) Y. Yokoyama and A. Yamauchi: Japan J. Mater. Sci. 30 (1993) 15-25.

6) K. Oguri, N. Iwataka, A. Tonegawa, Y. Hirose, K. Takayama and Y. Nishi: J. Mater. Res. 16 (2001) 553-557.

7) M. Faudree and Y. Nishi: Mater. Trans. 53 (2012) 1412-1419.

8) T. Takahashi, T. Morishita and Y. Nishi: J. Japan Inst. Metals 69 (2005) 759-762.

9) A. Mizutani and Y. Nishi: Mater. Trans. 44 (2003) 1857-1860.

10) Y. Nishi, M. Uyama, H. Kawazu, H. Takei, K. Iwata, H. Kudoh and K. Mitsubayashi: Mater. Trans. 53 (2012) 1657-1664.

11) A. Kasashima, N. Iwataka, J. Kawano, N. Honda and Y. Nishi: J. Adv. Sci. 9 (1997) 70-71.

12) Y. Miyazawa, M. Uyama, S. Ishii, M. Kanda and Y. Nishi: Mater. Trans. 54 (2013) 1166-1170.

13) M. Kanda, Y. Miyazawa, M. Uyama and Y. Nishi: Mater. Trans. 54 (2013) 1795-1799.

14) M. Kanda, K. Yuse, B. Guiffard, L. Lebrun, Y. Nishi and D. Guyomar: Mater. Trans. 53 (2012) 1806-1809.
15) M. Seno, K. Kurita, S. Yano and T. Sawaguchi: Basic Polymer Science (Kiso Koubunshikagaku in Japanese), (Kyouritsu Syuppan, Co., Ltd., 2000) pp. 128-129.

16) Y. Nishi, H. Sato, H. Takei and K. Iwata: J. Mater. Res. 24 (2009) 3503-3509.

17) R. Christenhusz and L. Reimer: Z. Angew. Phys. 23 (1967) 396-404.

18) W. F. Libby: Anal. Chem. 19 (1947) 2-6.

19) Y. Nishi, H. Kawazu, H. Takei, K. Iwata, H. Kudoh and K. Mitsubayashi: Mater. Trans. 52 (2011) 1943-1948.

20) T. Nishida and E. Yasuda: Evaluation of dynamic properties of ceramics (Ceramics no rikigaku tokusei hyouka in Japanese) (Nikkan Kogyo Shimbun Ltd., Tokyo, 1986) pp. 50-51.

21) H. Takei, M. Salvia, A. Vautrin, A. Tonegawa and Y. Nishi: Mater. Trans. 52 (2011) 734-739.

22) K. Iwata and Y. Nishi: Mater. Trans. 49 (2008) 2058-2062.

23) Y. Nishi, H. Kobayashi and M. Salvia: Mater. Trans. 48 (2007) $1924-$ 1927.

24) N. Tsuchikura, M. C. Faudree and Y. Nishi: Mater. Trans. 54 (2013) 371-379.

25) H. Takei, K. Iwata, M. Salvia, A. Vautrin and Y. Nishi: Mater. Trans. 51 (2010) 2259-2265.

26) W. Weibull: Ingeniörs vetenskaps akademien, nr. 153, (Generalstabens litografiska anstalts förlag, Stockholm, 1939) pp. 16-22.

27) Y. P. Yampolskii: Russ. Chem. Rev. 76 (2007) 59-78. 